\title{
Repair of a chondral defect using a cell free scaffold in a young patient - a case report of successful scaffold transformation and colonisation
}

\author{
Karl F Schüettler ${ }^{1}$, Johannes Struewer ${ }^{1}$, Marga B Rominger ${ }^{2}$, Peter Rexin ${ }^{3}$ and Turgay Efe ${ }^{{ }^{*}}$
}

\begin{abstract}
Background: Chondral defects of the articular surface are a common condition that can lead to osteoarthritis if not treated. Therapy of this condition is a topic of constant debate and a variety of chondral repair strategies are currently used. One strategy involves implantation of a cell-free matrix of type I collagen (COL1), to provide a scaffold for chondrocyte migration and proliferation and extracellular matrix production. Although several studies have suggested that chondrocytes can move, to the best of our knowledge there is still no proof of chondrocyte occurrence in a former cell-free scaffold for articular cartilage repair in humans.
\end{abstract}

Case presentation: An 18-year-old male patient underwent arthroscopic surgery of the knee for patellar instability and a chondral defect of the femoral condyle. Clinical outcome scores were recorded pre-operatively, after 6 weeks and after 6, 12, 24 and 36 months. MRI was recorded after 6 weeks and after 6, 12, 24 and 36 months postoperatively. At 42 months after implantation of a cell-free type I collagen matrix and reconstruction of the medial patellofemoral ligament, the patient was again treated arthroscopically for a tear of the medial meniscus of the same knee. A biopsy of the previous chondral defect was taken during arthroscopy for histological examination.

Conclusion: In addition to good clinical and radiological results reported for cell-free scaffolds for cartilage repair in several other studies, transformation of the scaffold could be observed during re-arthroscopy for the meniscal tear. Histological examination of the specimen revealed articular cartilage with vital chondrocytes and a strong staining reaction for type II collagen $(\mathrm{COL} I \mathrm{I})$, but no reaction for type I collagen staining. This might indicate a complete transformation of the scaffold and supports the theory that cell free scaffolds could support cell migration. Although the cell source remains unclear, migrating chondrocytes from the periphery remain a possibility.

Keywords: Vital chondrocyte, Cell-free scaffold, Histological examination, Chondrocyte migration

\section{Background}

Articular surface chondral and osteochondral lesions are a common problem, affecting patients in all age groups. Curl et al. assessed the patient population that might benefit from cartilage grafting by reviewing 31,516 knee arthroscopies performed between June 1991 and October 1995 [1]. Cartilage lesions were documented for 19,827 patients (63\%). Lesions caused by traumatic injuries,

\footnotetext{
* Correspondence: efet@med.uni-marburg.de

${ }^{1}$ Department of Orthopedics and Rheumatology, University Hospital

Marburg, Baldingerstrasse, 35043, Marburg, Germany

Full list of author information is available at the end of the article
}

degenerative joint disease or osteochondritis dissecans led to osteoarthritis of the affected joint $[2,3]$.

Several different treatments are available for small articular chondral defects, such as osteochondral transfer and bone marrow stimulation [4-6]. However, repair tissue after bone marrow stimulation has limited biochemical and biomechanical properties, and donor site morbidity has an adverse effect on the outcome of osteochondral transfer $[7,8]$. Brittberg et al. were the first to describe autologous chondrocyte implantation as a new treatment for articular chondral defects [9]. Over time, this method has evolved resulting in matrix-

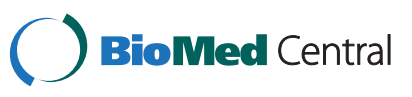




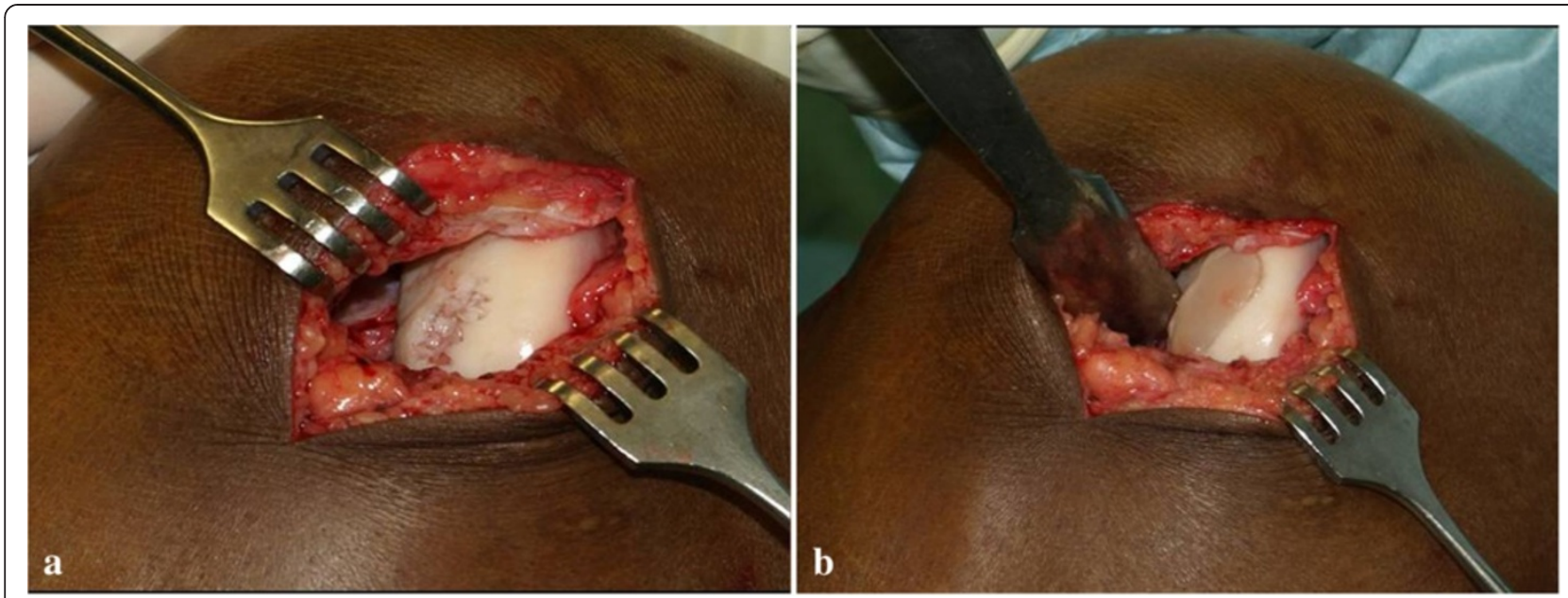

Figure 1 Intraoperative situs of the scaffold implantation.

Table 1 MOCART scores over time ( $w=$ weeks, $m=$ months)

\begin{tabular}{|c|c|c|c|c|c|c|}
\hline \multirow[t]{2}{*}{ Item } & \multirow[t]{2}{*}{ Scoring } & \multicolumn{5}{|c|}{ Follow-up } \\
\hline & & $6 w$ & $6 \mathrm{~m}$ & $12 \mathrm{~m}$ & $24 \mathrm{~m}$ & $36 \mathrm{~m}$ \\
\hline \multirow[t]{5}{*}{ Defect filling } & Complete $=20$ & 20 & 20 & 20 & 20 & 20 \\
\hline & Hypertrophy $=15$ & & & & & \\
\hline & Filling $>50 \%=10$ & & & & & \\
\hline & Filling $<50 \%=5$ & & & & & \\
\hline & Bone exposed $=0$ & & & & & \\
\hline \multirow[t]{4}{*}{ Integration with border zone } & Complete $=15$ & 10 & 10 & 15 & 15 & 15 \\
\hline & Split $=10$ & & & & & \\
\hline & Integration $>50 \%=5$ & & & & & \\
\hline & Integration $<50 \%=0$ & & & & & \\
\hline \multirow[t]{3}{*}{ Surface of repair tissue } & Intact $=10$ & 10 & 10 & 10 & 10 & 10 \\
\hline & $>50 \%=5$ & & & & & \\
\hline & $<50 \%=0$ & & & & & \\
\hline \multirow[t]{2}{*}{ Structure of repair tissue } & Homogeneous $=5$ & 0 & 0 & 0 & 5 & 5 \\
\hline & Nonhomogeneous $=0$ & & & & & \\
\hline \multirow[t]{2}{*}{ Signal intensity for repair tissue } & Normal $=30$ & 0 & 0 & 15 & 15 & 15 \\
\hline & Nearly normal = 15 & & & & & \\
\hline \multirow[t]{3}{*}{ Subchondral lamina } & Abnormal $=0$ & 5 & 5 & 5 & 5 & 5 \\
\hline & Intact $=5$ & & & & & \\
\hline & Non-intact $=0$ & & & & & \\
\hline \multirow[t]{2}{*}{ Subchondral bone } & Intact $=5$ & 5 & 5 & 5 & 5 & 5 \\
\hline & Non-intact $=0$ & & & & & \\
\hline \multirow[t]{2}{*}{ Adhesions } & $\mathrm{No}=5$ & 5 & 5 & 5 & 5 & 5 \\
\hline & Yes $=0$ & & & & & \\
\hline \multirow[t]{2}{*}{ Effusion } & $\mathrm{No}=5$ & 0 & 5 & 5 & 5 & 5 \\
\hline & Yes $=0$ & & & & & \\
\hline Final score & & 55 & 60 & 80 & 85 & 85 \\
\hline
\end{tabular}


induced autologous chondrocyte growth on 3D scaffolds $[10,11]$. Although these techniques show promising results, they still have some limitations, such as high costs for the cell culture required, a time-consuming two-step procedure and donor site morbidity due to chondrocyte harvesting.

The next evolutionary step has been the use of cellfree scaffolds [12]. The basic principle of this procedure is the use of a cell-free type I collagen (COL1) matrix to fill the cartilage defect with a suitable matrix for chondrocyte migration and proliferation and production of extracellular matrix. Further advantages of these cellfree matrices are the one-step surgical procedure and avoidance of defects from cell harvesting. This technique shows promising clinical results [13].

Although possible mechanisms underlying chondrocyte mobility have been discussed [14] and promising data from animal models are available [12,15], proof of chondrocyte ingrowth and matrix transformation is still lacking for human patients.

\section{Case presentation}

In August 2008, an 18-year-old male was admitted to our department for recurrent dislocation of the patella. Physical examination revealed a free range of motion (ROM; extension/flexion $0-0-130^{\circ}$ ) and a stable femoral-tibial joint with negative Lachmann and pivot shift tests. Diagnostic management included plain radiographs showing lateralisation of the patella. Magnetic resonance images (MRI) showed rupture of the medial patellofemoral ligament (MPFL) and a chondral lesion of the femoral condyle. The patient had suffered four redislocations, the last one without spontaneous reduction, so we performed MPFL reconstruction according to Schottle et al. [16] using the ipsilateral gracilis tendon and implanted a cell-free COL1 matrix $\left(\mathrm{CaReS}-1 \mathrm{~S}^{\circledR}\right.$, Arthro-Kinetics, Krems, Austria) for treatment of the chondral lesion. The scaffold represents a threedimensional collagen gel consisting of $4.8 \mathrm{mg} / \mathrm{mL}$ type I collagen derived from rat tails. The diameter was $15 \mathrm{~mm}$ and the thickness was $6 \mathrm{~mm}$. The matrix was stored in sterile phosphate-buffered saline solution and preserved at $4^{\circ} \mathrm{C}$ until use.

The cell-free scaffold was implanted via a medial miniarthrotomy. The chondral defect was carefully prepared using a cutter and a sharp angulated curette; the underlying subchondral bone was intact and without additional bleeding into the defect. The scaffold was implanted in a press-fit manner and showed complete congruity with the surrounding cartilage surface (Figure 1). The arthrotomy was closed layer-wise in a standard procedure.

The postoperative rehabilitation program started with immobilisation of the knee joint for 2 days. Then the

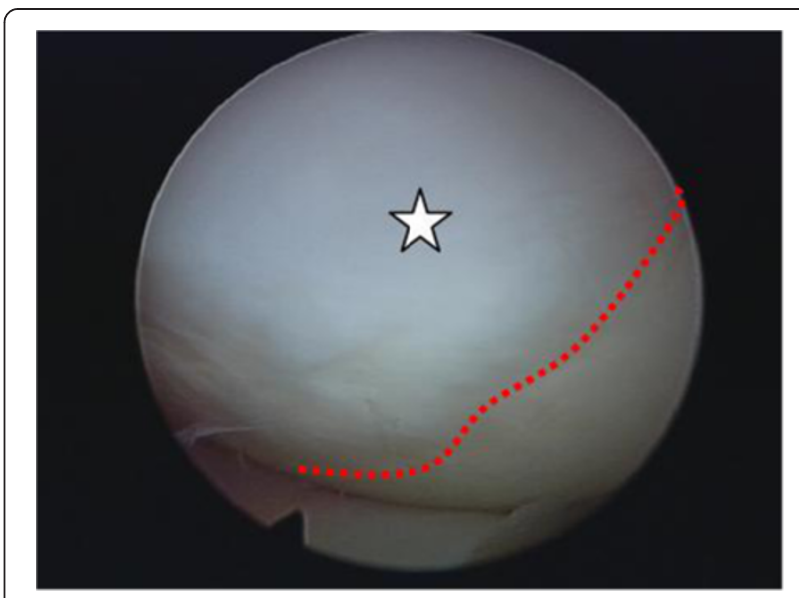

Figure $\mathbf{2}$ Intraoperative view of the scaffold $\mathbf{4 2}$ months after implantation (white banner).

patient was mobilised using two crutches with toe-touch weight bearing and limitation of flexion to $30^{\circ}$ for the next 2 weeks (ROM extension/flexion $0-0-30^{\circ}$ ). From 3 to 6 weeks after surgery, flexion was allowed up to $90^{\circ}$ and consecutively full weight bearing was achieved. Full ROM was allowed 6 weeks after surgery.

Follow-up was scheduled for 6 weeks and 6, 12, 24 and 36 months after surgery. MRI and functional, clinical and subjective assessment using the visual analogue scale (VAS [17]), the International Knee Documentation Committee scale (IKDC [18]) and the Tegner-Lysholm activity scale (Tegner [19]) were performed. MR images were scored according to the Magnetic Observation of Cartilage Repair Tissue (MOCART) scale (Table 1) [20,21].

All MR images were obtained with a 1.5-Tesla MRI Scanner MAGNETOM Espree (Siemens, Erlangen, Germany). A knee coil with a field of view of $18 \mathrm{~cm}$ was used with the knee positioned in extension. The following standardised sequences were recorded for coronal, sagittal and transverse slice orientations: proton density turbospin-echo fast suppression (320 9 320; thickness $3 \mathrm{~mm}$; repeat time (TR) 3,000 ms; echo time (TE) $37 \mathrm{~ms}$ ); T1 (384 9 384; thickness 3 mm; TR $411 \mathrm{~ms}$; TE $13 \mathrm{~ms}$ ); T1-volume-interpolated breathhold examination (280 9 320; thickness $1.5 \mathrm{~mm}$, TR 16; TE 7); and T2 (512 9 512; thickness $3 \mathrm{~mm}$; TR $460 \mathrm{~ms}$; TE $15 \mathrm{~ms}$ ).

Table 2 Changes in clinical scores over time ( $w=$ weeks, $\mathbf{m}=$ months)

\begin{tabular}{lllllll}
\hline Score & Preoperative & \multicolumn{5}{c}{ Follow-up } \\
\cline { 3 - 6 } & & $\mathbf{6} \mathbf{~ w}$ & $\mathbf{6} \mathbf{~ m}$ & $\mathbf{1 2} \mathbf{~}$ & $\mathbf{2 4} \mathbf{~}$ & $\mathbf{3 6} \mathbf{~ m}$ \\
\hline IKDC & 66 & 84 & 100 & 90 & 90 & 91 \\
VAS & 2 & 0 & 0 & 2 & 1 & 1 \\
Tegner & 3 & 2 & 4 & 2 & 2 & 2 \\
\hline
\end{tabular}




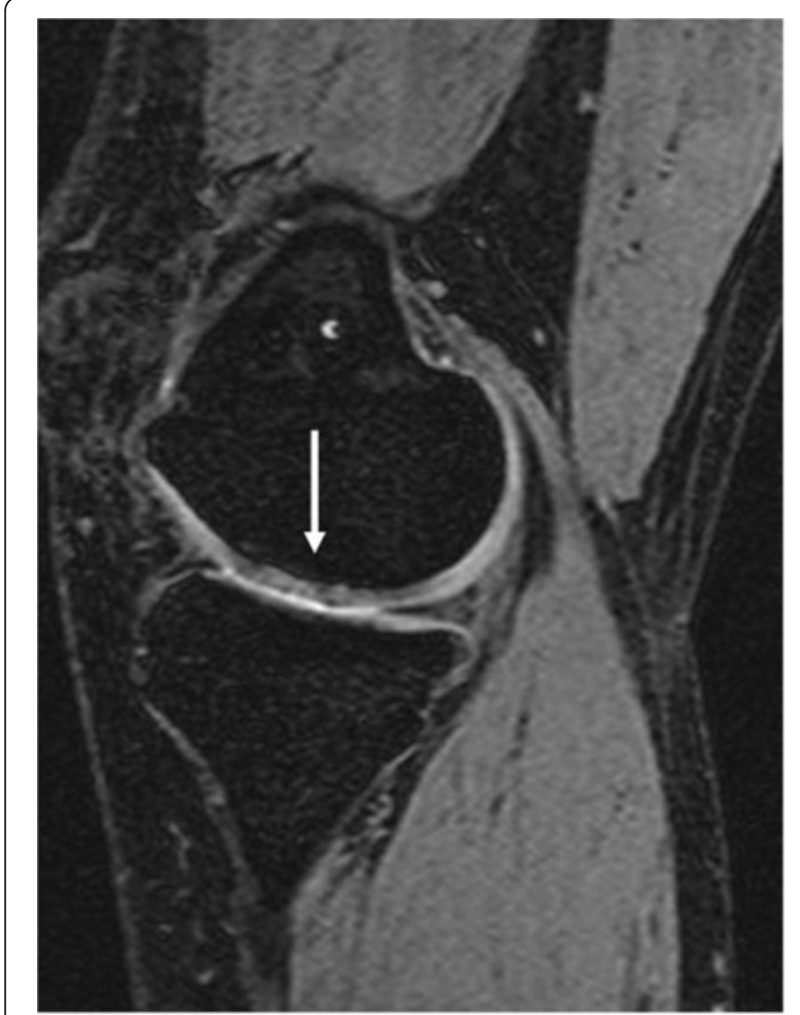

Figure 3 Follow-up MRI taken 36 months after surgery showing the cell-free scaffold (white arrow).
In 2012 the same patient, now 22 years old, underwent arthroscopic surgery of the same knee, this time for a medial meniscal tear. Preoperative MRI showed a displaced medial meniscal tear. Before surgery, the patient gave informed consent for biopsy from the grafted chondral defect. The meniscal tear was repaired using arthroscopic sutures in all-inside technique with FasT-Fix (Smith\&Nephew, Marl, Germany). The previous chondral defect showed good implant integration, with no signs of inflammation or dislocation (Figure 2) and a biopsy specimen was taken for histological examination using a spinal needle. The patient recovered quickly after arthroscopic surgery. Rehabilitation included partial weight-bearing exercise and limitation of flexion to $60^{\circ}$ for 3 weeks. Full weight-bearing and a full ROM were achieved in week 6 after surgery.

\section{Histological preparation}

Directly after surgery the specimen was fixed, decalcified and embedded using a standard procedure (24 h in $4 \%$ formalin, rinsed for $2 \mathrm{~h}$ with sterile water, decalcification in EDTA for $12 \mathrm{~h}$, dehydration in increasing ethanol concentrations and standard paraffin embedding).

Slices of 3 to $4 \mu \mathrm{m}$ were taken and stained after clearing the paraffin and rehydration. A CaReS- $1 S^{\circledR}$ cell-free scaffold was treated in exactly the same way for comparison. We first performed standard haematoxylin and eosin (H\&E) staining, then immunhistochemical staining for COL1 and COL2. The primary COL1 antibody was a goat polyclonal antibody against COL1A1 (D-13, sc-25974, Santa Cruz Biotechnology, Santa Cruz, CA, USA; 1:50). The primary COL2 antibody was a mouse monoclonal antibody against COL2 clone 6B3 (MAB8887, Chemicon International, 1:200). The

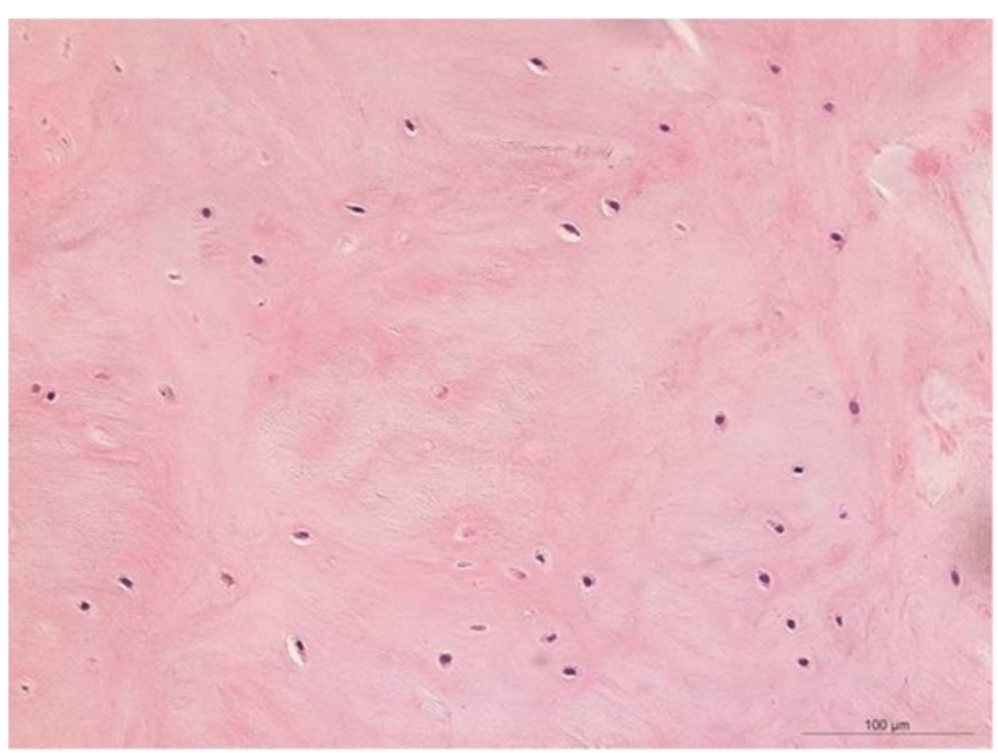

Figure 4 H\&E staining of regenerated cartilage showing vital chondrocytes and no signs of inflammation or abnormal calcification (magnification $200 \times$ ). 


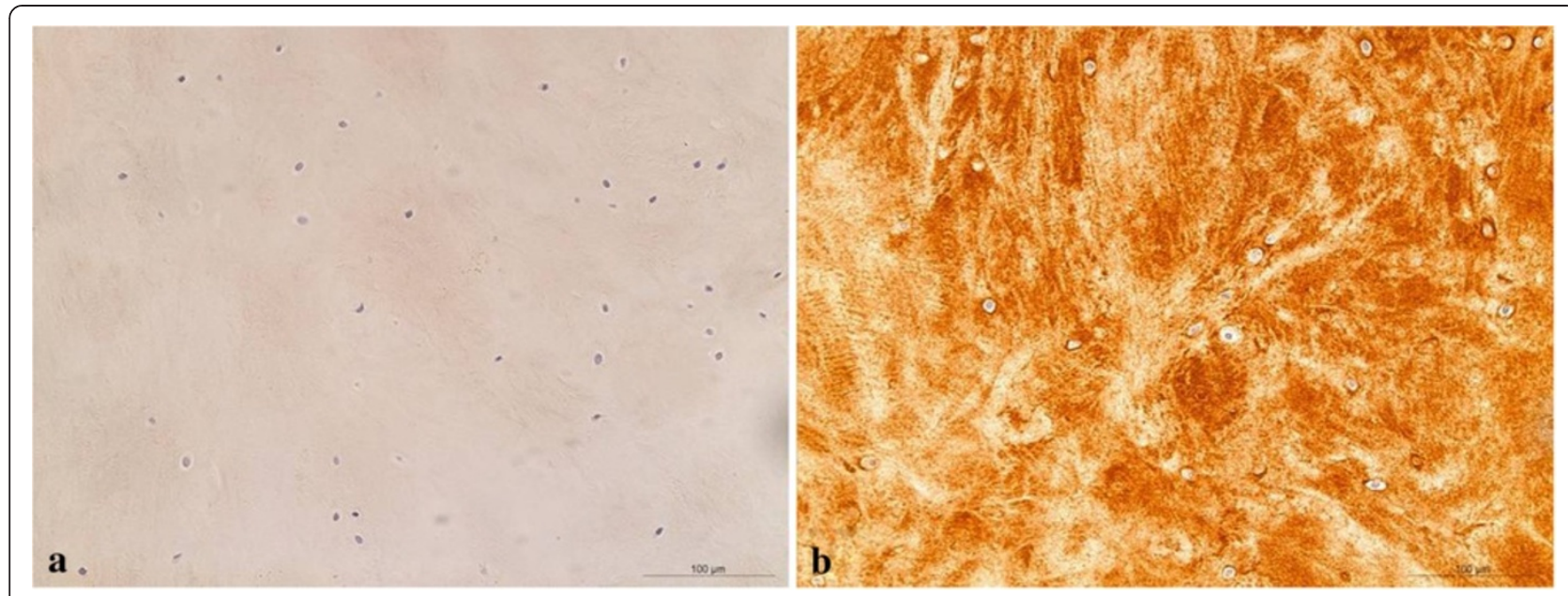

Figure 5 Regenerated cartilage showing no reaction for type I collagen (a) and a strong staining reaction for cartilage II collagen (b).

secondary COL1 antibody was a biotinylated anti-goat IgG antibody. For COL2 we used a peroxidase-labelled polyclonal antibody (HRP rabbit/mouse, Ref. V5007, Dako Envison Kit) with 3,3/-diaminobenzidine as chromogen.

\section{Results}

The clinical results were favourable and an improvement in function and a decrease in pain were evident from preoperative values (Table 2). Representative MRI image at 36 months postoperatively is shown in Figure 3. Using the MOCART scoring system there was a constant improvement from preoperative to 36 months postoperatively, indicating that the implant was correctly positioned and intact (Table 1).

H\&E staining showed nests of vital mononuclear isomorphic chondrocytes (Figure 4) within the regeneration tissue. There were no signs of inflammation, abnormal calcification or scar tissue. Immunohistological staining of the specimen showed a strong localisation for COL2 and no localisation for COL1 (Figures $5 \mathrm{a}$ and $\mathrm{b}$ ), thus showing no trace of the former scaffold-matrix. In comparison, the bare scaffold stained as a negative control showed a strong staining reaction for COL1 and no reaction for COL2 (Figures 6a and b).

In summary, the specimen showed the typical appearance of articular cartilage, with no signs of remaining scaffold material, no abnormal calcification within the regeneration tissue and no signs of scar tissue.

\section{Discussion}

The most important finding in the present case was that in addition to favourable clinical, functional and radiographic results, transformation of the cell-free COL1 scaffold took place. The biopsy showed no signs of remaining COL1, but instead showed COL2 with embedded vital chondrocytes.

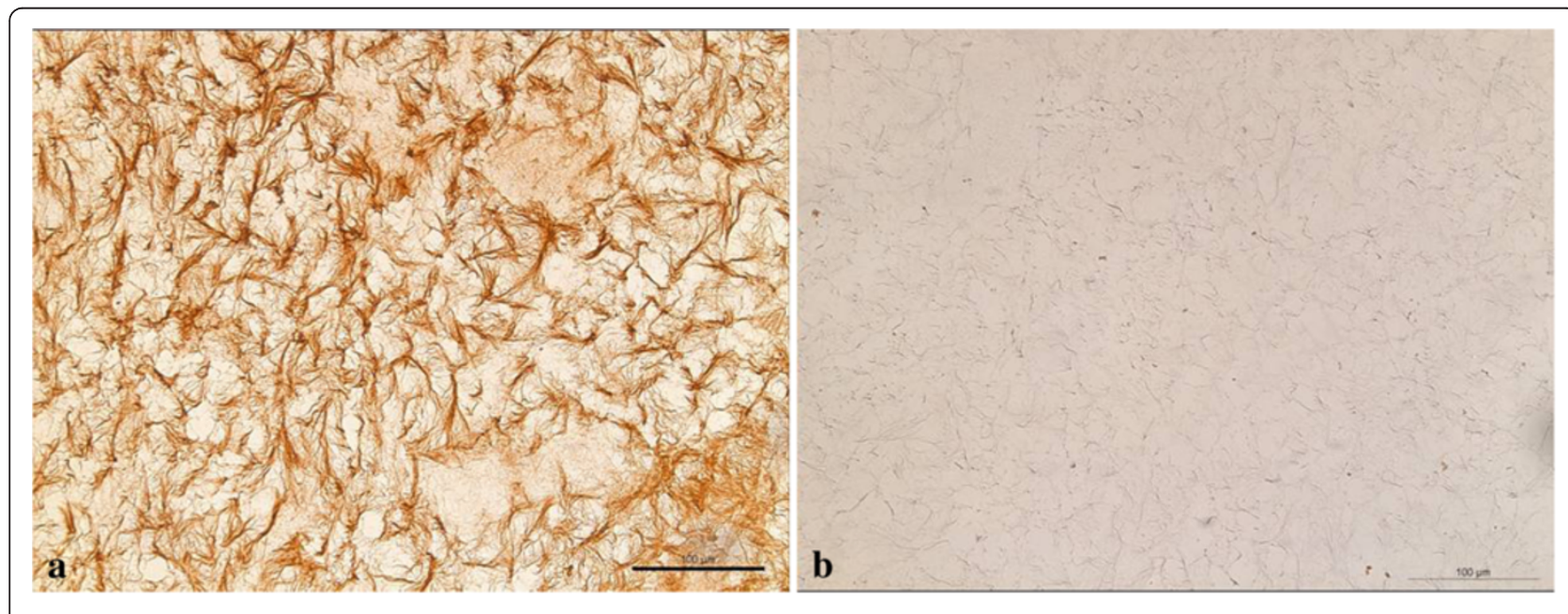

Figure 6 Scaffold showing a strong staining reaction for cartilage I collagen (a) and showing no reaction for type II collagen (b). 
Several studies have shown that the use of cell-free scaffolds leads to favourable results comparable to those for cell-seeded scaffolds in different animal models $[10,12]$. Similar results regarding clinical and morphologic outcome after implantation of cell-free COL1 matrices in humans were recently published [13].

The clinical course for the present case is in line with these results. After implantation of the cell-free scaffold, clinical, functional and morphological assessment revealed continuing improvement over time. The deterioration in results at the latest follow-up can undoubtedly be attributed to the traumatic meniscal tear the patient suffered. This injury also explains the slight deterioration in MOCART score due to the accompanying effusion, which is not associated with the implanted scaffold itself.

Histological and immunohistological results showed vital chondrocytes and a complete transformation of the cell-free COL1 matrix into a COL2 matrix. The cell-free COL1 scaffold thus facilitated the formation of good quality repair tissue - as confirmed by clinical, functional and morphologic assessment - with the histological appearance of articular cartilage.

Some open questions nonetheless still remain. Where did the chondrocytes that were found in the specimen come from? If they migrated from the perilesional tissue, how does chondrocyte migration occur and what cellular mechanisms are involved?

Morales reviewed the literature on chondrocyte movement in 2007 [14]. Although data on in vitro and in vivo examinations of chondrocyte motility were available at that time, the author concluded that in vivo chondrocyte motility remained to be proven.

Since the underlying bone was not penetrated, ingrowth from this direction seems rather unlikely but can not be excluded. Migration into the scaffold from the surrounding articular cartilage seems more likely; Lyman et al. [22] recently observed chondrocytes lining the margins of purposely created defects in an ex vivo organ model of human articular cartilage after 3-4 weeks in culture. Another possible origin of these cells could be traced to the presence of chondroprogenitor cells, which are also localised in the surrounding cartilage $[23,24]$. A further potential origin of these cells might be the synovial fluid which contains mesenchymal progenitor cells that could possibly integrated into the scaffold and differentiated into chondrocytes [25].

Another unresolved question is the underlying biomechanics that enables cells to move into the scaffold. Both adult chondrocytes and chondroprogenitor cells are usually located within a proteoglycan-rich pericellular matrix of fibrillar collagen, so any theory concerning cell movement must explain how this obstacle to motility could be overcome. Two main ideas are discussed in the literature. One is based on the observations of Lee et al. [26], who showed that chondrocytes can interact with surrounding collagen fibres by bending them, and thus they could possibly move along these fibres. The other is based on the involvement of proteolytic activity in tissue invasion, as observed by Werb [27] and Mignatti et al. [28], which could enable chondrocytes to enzymatically digest and resynthesise their direct environment; such a process would not only allow movement, but could possibly account for synthesis of a COL2 matrix.

A potential bias concerning the presented successful treatment of this young patient represents the patient's very young age. With regard to literature there is no information concerning the influence of biological or chronological age on healing response or scaffold transformation in the treatment of articular cartilage defects with cell-free scaffolds. Therefore additional information concerning larger patient collectives including different age groups is needed in order to recommend cell free scaffold as a general treatment procedure for articular cartilage defects.

\section{Conclusion}

The case of this patient showed that cell-free COL1 scaffold could provide a suitable matrix allowing for cellular repopulation and synthesis of a COL2 structure in an articular chondral defect of the knee. To determine the origin of these cells and how exactly they move into the scaffold, further investigations are needed.

\section{Consent}

Informed consent was obtained for taking the biopsy during arthroscopic treatment for the meniscal tear as well as for publishing the resulting data.

\section{Abbreviations}

COL I: Type I collagen; COL II: Type II collagen.

\section{Competing interests}

TE is consultant to Smith\&Nephew, Endoscopy, Germany. The magnetic resonance imaging was supported by a research fund of Arthro Kinetics.

\section{Authors' contribution}

KFS mainly drafted the manuscript and aided in the follow-up examinations. JS provided critical revision and did aid in drafting of the manuscript. MBR was the leading radiologist and examined the magnetic resonance images. PR was the leading pathologist and provided the histological examinations. TE performed the surgery, carried out the follow-up examinations, and did aid in drafting and proofreading the manuscript. All authors read and approved the final manuscript.

\section{Author details}

'Department of Orthopedics and Rheumatology, University Hospital Marburg, Baldingerstrasse, 35043, Marburg, Germany. ${ }^{2}$ Department of Radiology, University Hospital Marburg, Baldingerstrasse, 35043, Marburg, Germany. ${ }^{3}$ Institute of Pathology, University Hospital Marburg,

Baldingerstrasse, 35043, Marburg, Germany.

Received: 17 October 2012 Accepted: 5 April 2013

Published: 16 April 2013 


\section{References}

1. Curl WW, Krome J, Gordon ES, Rushing J, Smith BP, Poehling GG: Cartilage injuries: a review of 31,516 knee arthroscopies. Arthroscopy 1997, 13(4):456-460

2. Alford JW, Cole BJ: Cartilage restoration, part 1: basic science, historical perspective, patient evaluation, and treatment options. Am J Sports Med 2005, 33(2):295-306.

3. Sellards RA, Nho SJ, Cole BJ: Chondral injuries. Curr Opin Rheumatol 2002, 14(2):134-141.

4. Hangody L, Vasarhelyi G, Hangody LR, Sukosd Z, Tibay G, Bartha L, Bodo G: Autologous osteochondral grafting-technique and long-term results. Injury 2008, 39(Suppl 1):S32-S39.

5. Steadman JR, Rodkey WG, Rodrigo JJ: Microfracture: surgical technique and rehabilitation to treat chondral defects. Clin Orthop Relat Res 2001, 391(Suppl):S362-S369.

6. Steadman JR, Briggs KK, Rodrigo JJ, Kocher MS, Gill TJ, Rodkey WG: Outcomes of microfracture for traumatic chondral defects of the knee: average 11-year follow-up. Arthroscopy 2003, 19(5):477-484.

7. Bae DK, Yoon $\mathrm{KH}$, Song SJ: Cartilage healing after microfracture in osteoarthritic knees. Arthroscopy 2006, 22(4):367-374.

8. Gobbi A, Nunag P, Malinowski K: Treatment of full thickness chondral lesions of the knee with microfracture in a group of athletes. Knee Surg Sports Traumatol Arthrosc 2005, 13(3):213-221.

9. Brittberg M, Lindahl A, Nilsson A, Ohlsson C, Isaksson O, Peterson L: Treatment of deep cartilage defects in the knee with autologous chondrocyte transplantation. N Engl J Med 1994, 331(14):889-895.

10. Gavenis K, Schmidt-Rohlfing B, Andereya S, Mumme T, Schneider U, Mueller-Rath R: A cell-free collagen type I device for the treatment of focal cartilage defects. Artif Organs 2010, 34(1):79-83.

11. Peretti GM, Pozzi A, Ballis R, Deponti D, Pellacci F: Current surgical options for articular cartilage repair. Acta Neurochir Suppl 2011, 108:213-219.

12. Schneider U, Schmidt-Rohlfing B, Gavenis K, Maus U, Mueller-Rath R, Andereya S: A comparative study of 3 different cartilage repair techniques. Knee Surg Sports Traumatol Arthrosc 2011, 19(12):2145-2152.

13. Efe T, Theisen C, Fuchs-Winkelmann S, Stein T, Getgood A, Rominger MB, Paletta JR, Schofer MD: Cell-free collagen type I matrix for repair of cartilage defects-clinical and magnetic resonance imaging results. Knee Surg Sports Traumatol Arthrosc 2012, 20(10):1915-1922.

14. Morales Tl: Chondrocyte moves: clever strategies? Osteoarthritis Cartilage 2007, 15(8):861-871.

15. Schagemann JC, Erggelet C, Chung HW, Lahm A, Kurz H, Mrosek EH: Cell-laden and cell-free biopolymer hydrogel for the treatment of osteochondral defects in a sheep model. Tissue Eng Part A 2009, 15(1):75-82.

16. Schottle $P$, Schmeling $A$, Romero J, Weiler A: Anatomical reconstruction of the medial patellofemoral ligament using a free gracilis autograft. Arch Orthop Trauma Surg 2009, 129(3):305-309.

17. Flandry F, Hunt JP, Terry GC, Hughston JC: Analysis of subjective knee complaints using visual analog scales. Am J Sports Med 1991 19(2):112-118

18. Irrgang JJ, Anderson AF, Boland AL, Harner CD, Kurosaka M, Neyret $P$, Richmond JC, Shelborne KD: Development and validation of the international knee documentation committee subjective knee form. Am J Sports Med 2001, 29(5):600-613.

19. Tegner Y, Lysholm J: Rating systems in the evaluation of knee ligament injuries. Clin Orthop Relat Res 1985, 198:43-49.

20. Marlovits S, Singer P, Zeller P, Mandl I, Haller J, Trattnig S: Magnetic resonance observation of cartilage repair tissue (MOCART) for the evaluation of autologous chondrocyte transplantation: determination of interobserver variability and correlation to clinical outcome after 2 years. Eur J Radiol 2006, 57(1):16-23.

21. Marlovits S, Striessnig G, Kutscha-Lissberg F, Resinger C, Aldrian SM, Vecsei $V$, Trattnig S: Early postoperative adherence of matrix-induced autologous chondrocyte implantation for the treatment of full-thickness cartilage defects of the femoral condyle. Knee Surg Sports Traumatol Arthrosc 2005, 13(6):451-457.

22. Lyman JR, Chappell JD, Morales TI, Kelley SS, Lee GM: Response of Chondrocytes to Local Mechanical Injury in an Ex Vivo Model. Cartilage 2012, 3(1):58-69.

23. Alsalameh S, Amin R, Gemba T, Lotz M: Identification of mesenchymal progenitor cells in normal and osteoarthritic human articular cartilage. Arthritis Rheum 2004, 50(5):1522-1532.
24. Dowthwaite GP, Bishop JC, Redman SN, Khan IM, Rooney P, Evans DJ, Haughton L, Bayram Z, Boyer S, Thomson B, et al: The surface of articular cartilage contains a progenitor cell population. J Cell Sci 2004, 117(Pt 6):889-897.

25. Filova E, Jelinek F, Handl M, Lytvynets A, Rampichova M, Varga F, Cinatl Soukup T, Trc T, Amler E: Novel composite hyaluronan/type I collagen/ fibrin scaffold enhances repair of osteochondral defect in rabbit knee. J Biomed Mater Res B Appl Biomater 2008, 87(2):415-424.

26. Lee GM, Loeser RF: Cell surface receptors transmit sufficient force to bend collagen fibrils. Exp Cell Res 1999, 248(1):294-305.

27. Werb Z: ECM and cell surface proteolysis: regulating cellular ecology. Cell 1997, 91(4):439-442.

28. Mignatti $P$, Robbins $E$, Rifkin DB: Tumor invasion through the human amniotic membrane: requirement for a proteinase cascade. Cell 1986, 47(4):487-498.

doi:10.1186/1471-2482-13-11

Cite this article as: Schüettler et al.: Repair of a chondral defect using a cell free scaffold in a young patient - a case report of successful scaffold transformation and colonisation. BMC Surgery 2013 13:11.

\section{Submit your next manuscript to BioMed Central and take full advantage of:}

- Convenient online submission

- Thorough peer review

- No space constraints or color figure charges

- Immediate publication on acceptance

- Inclusion in PubMed, CAS, Scopus and Google Scholar

- Research which is freely available for redistribution 